\title{
Animasi 3d Arsitektural Mix Dengan Motion Grafik Sebagai Media Promosi Perumahan Bhumi Nirwana
}

\author{
Adhi Latief Muktiana ${ }^{1}$ \\ Yusmedi Nurfaizal $^{2}$ \\ Informatika $^{1}$, Bisnis Digital ${ }^{2}$ Universitas Amikom Purwokerto \\ E-mail: adhilatiefm@gmail.com ${ }^{1}$; faizal@amikompurwokerto.ac.id ${ }^{2}$
}

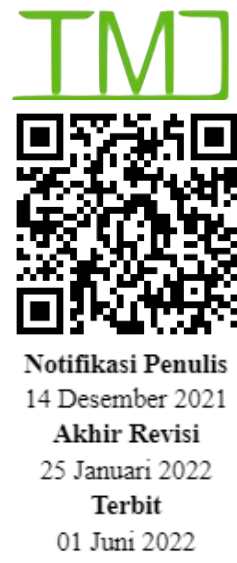

Muktiana, A. L., \& Nurfaizal, Y. (2022). Animasi 3D Arsitektural Mix Dengan Motion Grafik Sebagai Media Promosi Perumahan Bhumi Nirwana. Technomedia Journal, 7(1), 4052.

https://doi.org/10.33050/tmj.v7i1.1800

\begin{abstract}
ABSTRAK
Rumah merupakan harta terbesar bagi keluarga dan merupakan tempat tinggal paling utama. Dalam mempromosikan rumah, tentunya sangat banyak media promosi yang dipakai seperti media cetak atau media elektronik. PT.Anugrah Bumi Sejati adalah perusahaan yang bergerak dibidang properti dan pemasaran rumah. Selama ini perusahaan menggunakan media cetak sebagai media promosi yang memiliki banyak keterbatasan seperti calon pembeli tidakmengetahui informasi lebih mengenai detail rumah yang akan dibeli. Untuk itu, dengan membuat animasi 3D sebagai media promosi rumah pada PT. Anugrah Bumi Sejati diharapkanberdampak pada peningkatan penjualan. Animasi 3D ini dibuat menggunakan Teknik low poly dan Output yang dihasilkan berupa sebuah animasi 3D sebagai media promosi rumah pada PT. Anugrah bumi Sejati yang menampilkan exterior dan interior rumah. Sesuai dengan hasil Refrensi yang diperoleh penulis karena masih sangat perlunya 3D animasi untuk keperluan promosi perumahan, maka penulis akan melakukan penelitian yang bertujuan untuk membantu mepromosikan rumah yang akan di buat menggunakan 3D Modeling low poly dan di render menggunakan v-ray dan di mix dengan motion grafik. Hasil dari perancangan ini berupa rumah dalam bentuk 3D yang dapat digunakan sebagai media dan inovasi baru untuk pembeli rumah yang ingin di huni.
\end{abstract}

Kata kunci : Modeling 3D, Perumahan, Low poly, V-ray

\section{ABSTRACT}

The house is the greatest treasure for the family and is the most importantplace to live. In promoting the house, of course, there are many promotional media used, such as print media or electronic media. PT. Anugrah Bumi Sejati is a company engaged in property and home marketing. So far, companies use print media as a medium that has many limitations, such as potential buyers not knowing more information about the details of the house to be purchased. For that, by making 3D animation as a home promotion media at PT. Anugrah Bumi Sejati isexpected to have an impact on 
increasing sales. This $3 D$ animation is made usinglow poly technique and the resulting output is a $3 D$ animation as a home promotion medium at PT. Anugrah Bumi Sejati which displays the exterior and interior of the house. In accordance with the results obtained by the author because of the need for $3 D$ animation for housing promotion purposes, the author will conduct research that aims to help promote houses that will be made using $3 D$ Modeling low poly and rendered using v-ray and mixed with motion graphics. The result of this design is a house in $3 D$ that can be used as a new medium and innovation for home buyers who want to live in.

Keywords: Animasi 3D, Motion Grafik, Low poly, V-ray, Media Promosi

\section{PENDAHULUAN}

PT. Anugrah Bumi Sejati merupakan perusahaan yang bergerak di bidang developer, kontraktor, perdagangan umum dan jasa yang sudah terdaftar keanggotaan REI (Persatuan Perusahaan Realestate Indonesia) dengan nomor peserta NPA : 02-0733. Sedangkan salah satu produk yang di tawarkan adalah perumahan graha harmoni karanggintung dengan menyediakan dua type rumah 45 dan 54. Sistem pemasaran yang dilakukan PT Anugrah Bumi Sejati adalah menciptakan blog (http://anugrahbumipurwokerto.blogspot.com) dan Share di sosial media seperti Instagram dan Facebook selain melalui media online PT Anugrah Bumi Sejati juga menawarkan produknya melalui brosur untuk melihatkan denah perumahan secara langsung ke calon pembeli. Hasil dari pemasaran di PT. Anugrah Bumi Sejati dalam target penjualanya hanya 2 unit saja dari keseluruhan perumahan yang dipasarkan. Berdasarkan hasil interview dengan HRD dan karyawan PT.Anugrah Bumi Sejati membutuhkan sesuatu hal yang bisa mempromosikan untuk mencapai target penjualan dalam satu perumahan dengan detail yaitu video promosi animasi $3 \mathrm{~d}$ tentang perumahan tersebut supaya bisa dilihat langsung oleh calon pembeli rumah yang ingin di huni.

Media promosi merupakan cara komunikasi yang dilakukan oleh perusahaan kepada konsumen yang dituju, dengan tujuan menyampaikan informasi mengenai produk supaya mereka mau membeli [1]. Promosi terdiri dari periklanan, pemasaran langsung, penjualan perorangan, promosi penjualan dan hubungan masyarakat. Promosi merupakan salah satu bagian dari rangkaian kegiatan pemasaran suatu barang. Untuk mengandalkan promosi perusahaan harus menentukan dengan tepat media promosi yang akan dipergunakan supaya mencapai keberhasilan dalam pendistribusian [2], [3].

Penyampaian informasi produk atau properti dapat menggunakan media multimedia dengan tampilan tiga dimensi namun media tersebut juga harus sesuai dengan kebutuhan dari sistem untuk pemasaran, yaitu mudah digunakan dan diakses oleh pengguna. Keunggulan utama dari animasi 3D adalah visualisasi objek yang tampak lebih nyata dan mendekati bentuk aslinya. Keunggulan lain adalah kemampuannya untuk membuat dan mewujudkan visualisasi dengan yang sulit dan tidak mungkin atau bahkan yang nampak mustahil [4]. Media dengan tampilan tiga dimensi dapat diterapkan dalam metode animasi yang berupa film atau video sehingga media tersebut lebih fleksibel saat digunakaan. Dengan menggunakan media visualisasi diharapkan akan dapat informasi tambahan untuk memvisualkan bentuk rumah atau produk tampak luar (eksterior) atau dalam (interior). Sehingga masyarakat sebagai calon pembeli akan mendapat informasi tambahan seperti apa model dan tipe rumah yang ditawarkan dan dapat pertimbangan tentang produk yang 
ditawarkan. Berdasarkan konteks tersebut sebenarnya, media yang besifat teknologi multimedia visualisasi tiga dimensi animasi berupa video dapat menjadi pertimbangan untuk alat media penyampaian informasi [5], [6]. Dalam penelitian ini akan membuat media informasi dan promosi dengan merancang animasi tiga dimensi sebuah bangunan menggunakan teknik low poly yaitu perumahan bhumi nirwana sebagai media promosinya supaya dapat meningkatkan penjualan perumahan tersebut. Berdasarkan latar belakang tersebut penelitian ini bertopik untuk merancang visualisasi tiga dimensi perumahan menggunakan teknik low poly dan di render menggunakan v-ray sebagai media informasi pemasaran.

\section{PERMASALAHAN}

Berdasarkan latar belakang yang telah disebutkankan di atas, maka rumusan masalah dalam penulisan penelitian ini adalah, bagaimana membuat sebuah media informasi objek sebuah rumah divisualisasikan menjadi tiga dimensi dengan menggunakan teknik low poly dan dirender menggunakan v-ray.

\section{METODOLOGI PENELITIAN}

Penelitian ini merupakan jenis penelitian pengembangan (research and development), penelitian pengembangan didefinisikan sebagai suatu metode penelitian yang dipakai untuk menghasilkan produk tertentu dan menguji efektifitas produk tersebut. Penelitian ini menggunakan metode pengumpulan data yaitu melalui interview dan pengamatan langsung ke lokasi perumahan tersebut lalu meminta data - data informasi tentang perumahan tersebut.

1. Observasi, observasi biasa disebut pengamatan adalah salah satu teknik yang bertujuan untuk pengumpulkan data yang relevan untuk digunankan dalam mempelajari suatu sistem. Observasi dilakukan dengan melakukan pengamatan secara langsung untuk mencari data - data yang relevan terkait perumahan tersebut. Merupakan langkahlangkah pengumpulan data dengan melakukan pengamatan langsung terhadap objek yang diteliti. Untuk memperoleh data nyata dan meyakinkan penulis melakukan observasi langsung di Perumahan Bhumi Nirwana Karanggintung [7].

2. Wawancara, wawancara merupakan komunikasi dua arah yang bertujuan untuk mendapatkan informasi dari narasumber. Wawancara ini dilakukan untuk mendapatkan informasi yang terhubung dengan Perumahan Bhumi Nirwana yang saat ini sedang di teliti. wawancara dilakukan kepada HRD PT.Anugrah Bumi Sejati.

3. Studi pustaka dilakukan untuk mencari literature review mengenai perancangan media informasi atau promosi dengan animasi 3D supaya dapat dilihat langsung oleh konsumen.

4. Kuisioner merupakan teknik pengumpulan data yang dilakukan dengan cara memberikan serangkaian pertanyaan atau pernyataan tertulis kepada responden untuk dijawab.

Metode yang digunakan dalam pengembangan sistem dalam penelitian ini adalah Multimedia Development Lifecycle Method (MDLC). Multimedia Development Lifecycle Method (MDLC) ada enam tahapan yaitu konsep (concept), desain (design), pengumpulan bahan (material collection), perakitan (assembly), pengujian (testing) dan distribusi (distribution) [8]. 
1. Tahap Concept (konsep) bertujuan untuk menentukan sasaran atau identifikasi audience. Diawali dengan menentukan type rumah seperti apa yang akan divisualisasikan kemudian menentukan jenis video animasi, pada penelitian ini menggunakan animasi 3D dengan teknik lowpoly yang memperlihatkan bentuk rumah yang di pasarkan.

2. Design (Perancangan) merupakan tahap untuk membuat spesifikasi tentang perancangan animasi tersebut dari mulai bentuk, tampilan animasi dan kebutuhan bahan untuk membuat animasi tersebut. Pada tahap ini peneliti membuat sketsa rumah yang akan menjadi objek animasi tersebut karena peneliti melakukan wawancara yang hasilnya PT.Anugrah Bumi Sejati membutuhkan animasi 3d berupa rumah 2 type yaitu 54 dan 45 untuk mempromosikan secara digital.

3. Material Collecting adalah tahap mrngumpulkan material yang sesuai untuk pembuatan animasi. Untuk kebutuhan beberapa furniture dan environment peneliti melakukan wawancara kepada pihak PT.Anugrah Bumi Sejati dan mencari sumber lain dari internet. Kemudian peneliti membuat objek 3D dari gamber yang sudah dibuat pada brosur kemudian mendesain rumah sesui keinginan PT Anugrah Bumi Sejati.

4. Tahap Assembly (pembuatan) adalah tahap dimana semua material yang sudah dikumpukan kemudian disusun. Tahap design rumah dan environment peneliti menggunakan skechup 2020 karena animsi tersebut menggunakan animasi 3D. Kemudian untuk melakukan penggabungan semua scene yang telah dianimasikan dan memberikan sound effect serta narasi animasi, peneliti menggunakan Adobe Premiere Pro lalu dirender ke dalam format ".mp4".

5. Proses pengujian film animasi tersebut menggunakan 2 (dua) pengujian yakni pengujian alpha test dan beta test. Alpha test merupakan proses pengujian yang dilakukan oleh peneliti itu sendiri. Beta test adalah proses pengujian yang melibatkan pengguna akhir dan mengumpulkan ke pihak PT.Anugrah Bumi Sejati apakah sudah sesuai dengan yang diinginkan.

6. Tahap ini video animasi akan disimpan dalam sebuah media penyimpanan, tahap ini bisa digunakan sebagai evaluasi untuk pengembangan produk yang telah sesuai agar menjadi lebih baik. Output video animasi yang sudah dibuat akan dipublikasi melalui akun youtube peneliti dan pihak PT. Anugrah Bumi Sejati,

Media video animasi 3 dimensi dinilai mampu memberikan kontribusi dalam mempromosikan tempat wisata dengan mensimulasikan tempat wisata tersebut seperti aslinya [9] menunjukkan bahwa. Pentingnya memperhatikan desain dan fungsi dari elemen-elemen visual yang ada di motion graphic adalah untuk memberikan kenyamanan, kesan bagi penonton, dan informasi yang dapat dimengerti juga dipahami yang menunjukkan bahwa Animasi 3D sebagai media promosi untuk menjadikan para audience memahami detail dari produk knalpot. [10]

\section{HASIL DAN PEMBAHASAN}

Tahapan animasi 3D secara keseluruhan dikerjakan dengan media komputer, mulai dari tahap modeling, texturing, lighting, sampai rendering. Keunggulan utama dari animasi 
3D adalah visualisasi objek yang tampak lebih nyata dan mendekati bentuk aslinya. Keunggulan lain adalah kemampuannya untuk membuat dan mewujudkan visualisasi yang sulit dan tidak mungkin atau bahkan yang nampak mustahil [11]. Metode pengembangan sistem yang digunakan dalam penelitian ini adalah Multimedia Development Life Cycle (MDLC) versi Sutopo yang terdiri enam fase, yakni concept, design, material collection, assembly, testing dan distribution. Metode ini sangat sesuai untuk pengembang sistem multimedia. Tahapan pengembangan sistem dapat dijabarkan sebagai berikut:

\section{Pengonsepan (Consept)}

Animasi ini akan membantu pemasaran perumahan di PT. Anugrah Bumi Sejati dikarenakan pt tersebut masih menggunakan pemasaran dengan denah brosur saja dan hanya gambar tampak depan saja. Maka dari itu peneliti akan membantu dalam mempromosikan perumahan tersebut menggunakan 3D modeling supaya calon pembeli juga bisa melihat gambaran rumah yang ingin dihuni. Jenis project yang dibuat adalah sebuah video animasi 3d modeling yang memperlihatkan modeling rumah yang disuguhkan untuk dipilih pembeli dengan dua type yaitu type 45 dan 54 , dengan menggunakan Teknik low poly mesh polygon pada komputer grafis 3D yang memiliki jumlah polygon yang relatif lebih kecil. Low poly biasanya diterapkan pada aplikasi real-time.

2. Perancangan (Design)

Setelah tahap pengonsepan dilakukan selanjutnya masuk pada tahap perancangan untuk mendeskripsikan alur dari setiap scene. Ini adalah tahap pengumpulan bahan yang sesuai dengan kebutuhan yang dikerjakan. Bahan-bahan tersebut antara lain animasi, video, audio, dan lain-lain. Pada tahap ini menggunakan storyboard untuk mendeskripsikan dari setiap scene ke scene selanjutnya.

Tabel 1. Contoh Storyboard

\begin{tabular}{|c|c|c|c|c|}
\hline Scene & Sequence & Board & Durasi & Narasi \\
\hline 2 & 5 & & 00:00:03 & $\begin{array}{l}\text { Rumah } \\
\text { type } 45 \\
\text { Kamar } \\
\text { mandi }\end{array}$ \\
\hline
\end{tabular}




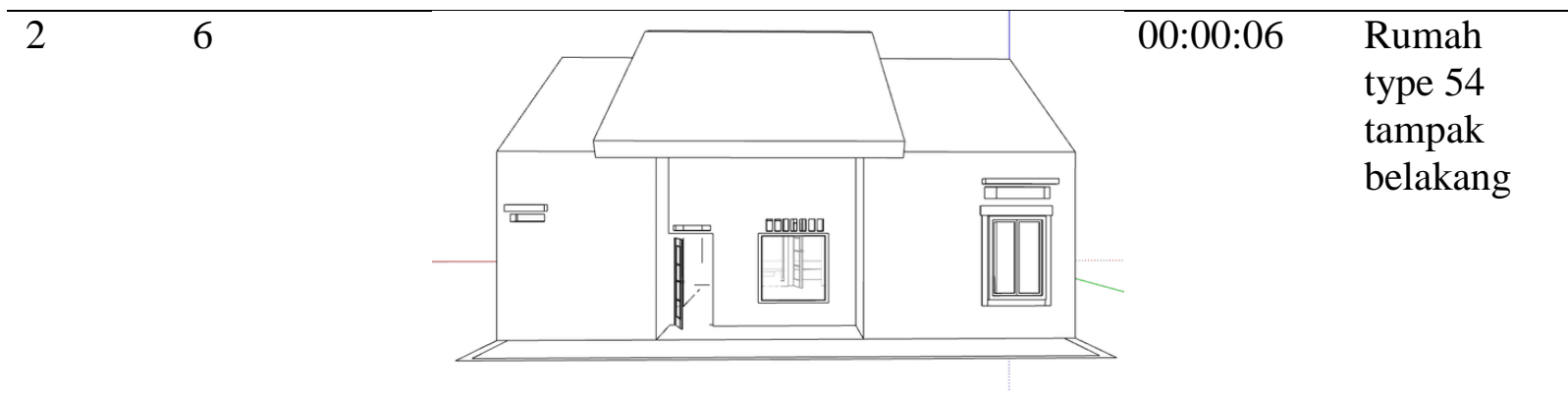

\section{Material Collecting}

Tahap pengumpulan material yang digunakan untuk pembuatan animasi seperti texture, furniture, narasi dan storyboard, selanjutnya dengan environment atau latar kejadian dalam animasi tersebut menggunakan Sketchup.

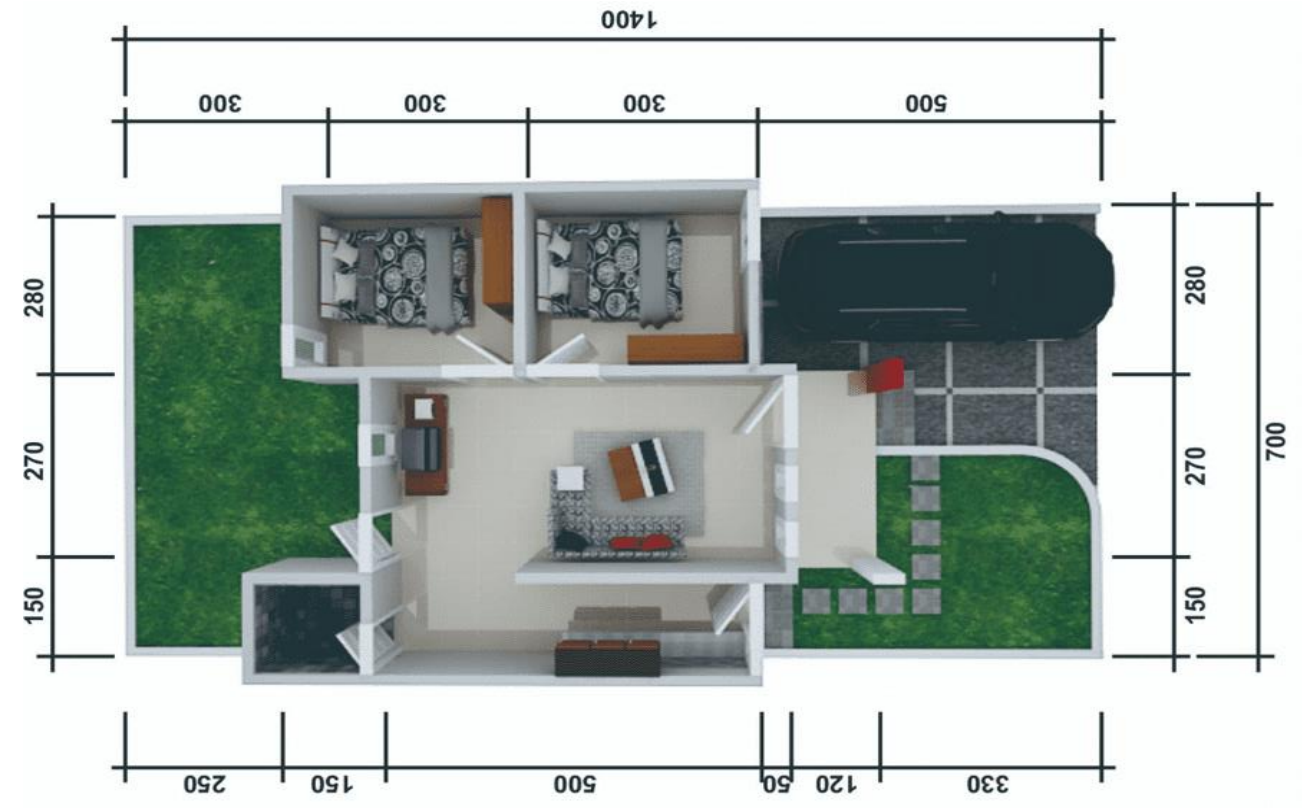

Gambar 1. Denah rumah type 45 


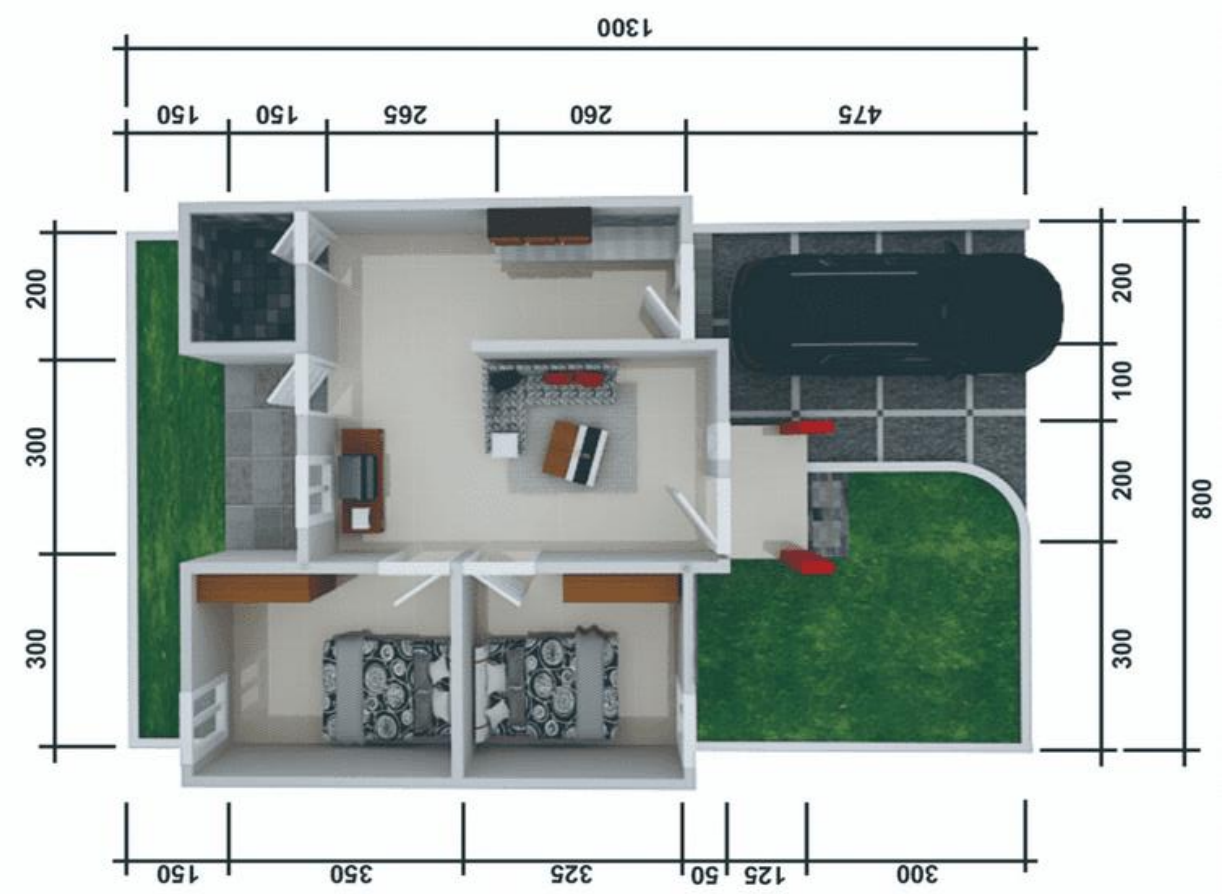

Gambar 2. Denah rumah type 54

Dari gambar 1 dan gambar 2. kedua denah ini yang diminta oleh pihak PT.Anugrah Bumi Sejati digunakan sebagai acuan untuk mendesain $3 \mathrm{~d}$ modelingnya karena output dari penelitian ini berupa video.

4. Assembly

Setelah bahan semuanya terkumpul kemudian dilanjutkan dengan penggabungan keseluruhan. Diawali dengan pemberian garis untuk membuat tembok rumah terlebih dahulu pada desain denah supaya sama seperti denah yang sudah di gambarkan. Tahap ini sebagai awal yang memebedakan dari penelitian sebelumnya karena tidak diberikan penjelasan denah rumah yang ingin di desain dan teknik yang digunakan untuk mendesain sebuah rumah.

Sedangkan pada gambar 3 dan gambar 4 menggunakan teknik lowpoly untuk mempermudah peneliti mendesain $3 d$ modeling sebuah bengunan.

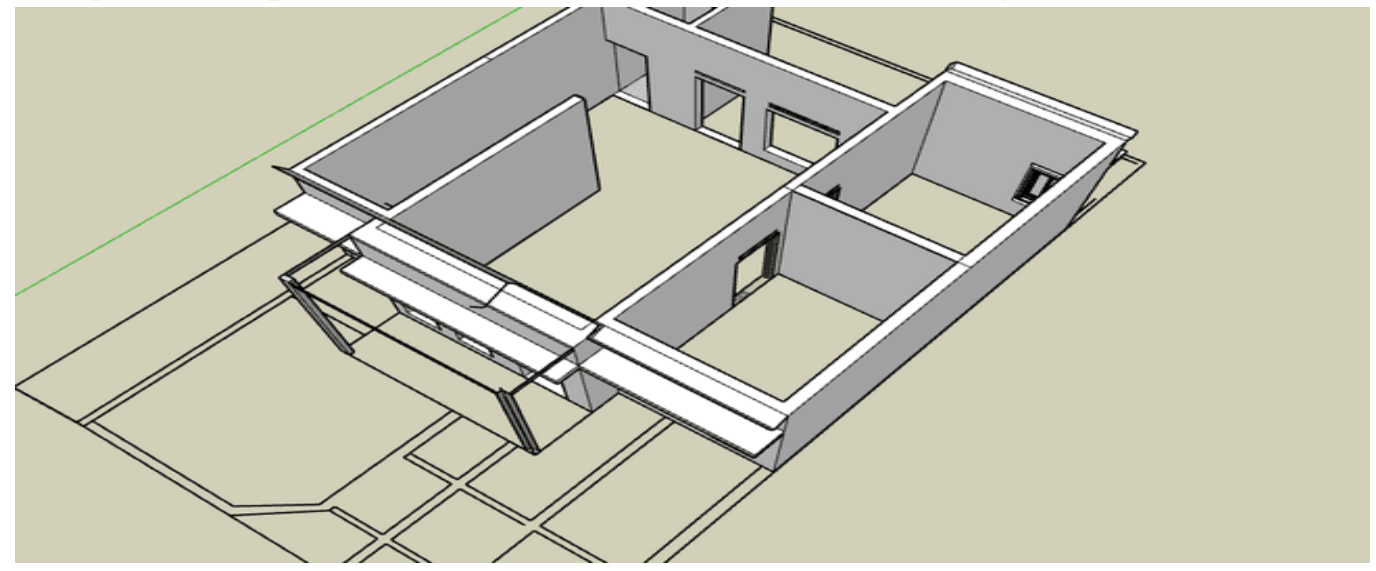

Gambar 2. Modeling rumah type 45 


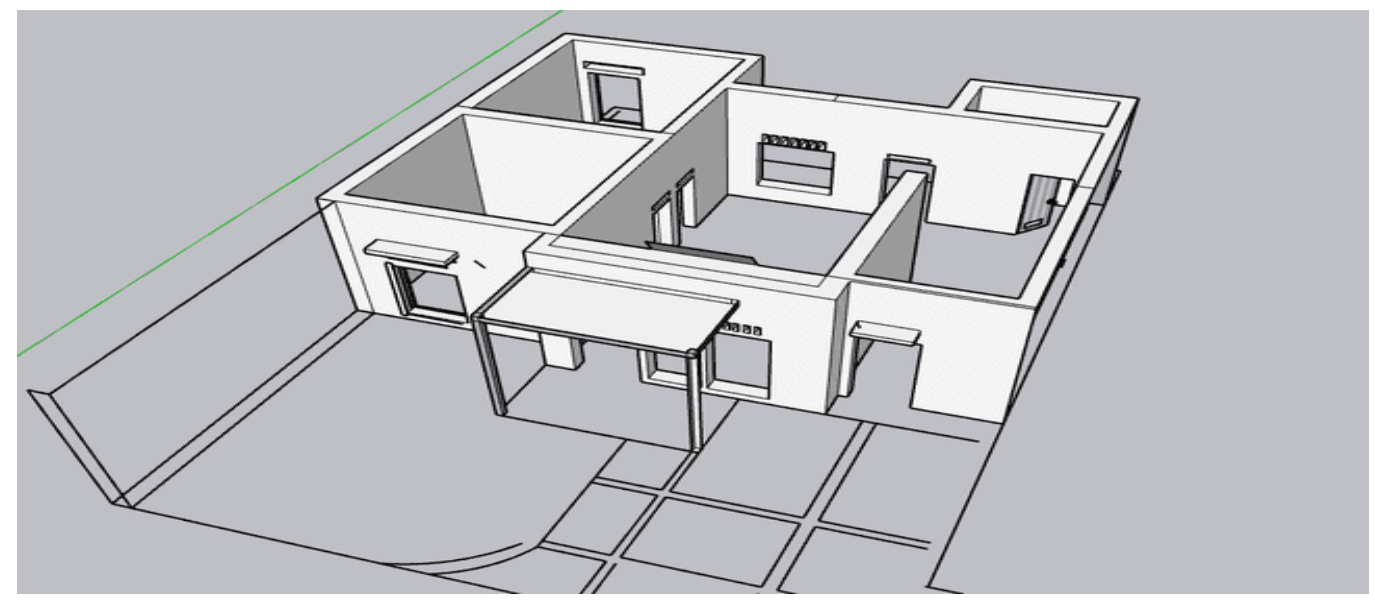

Gambar 3. Modeling rumah Type 54

Selanjutnya tahap texturing untuk memberi permukaan objek.
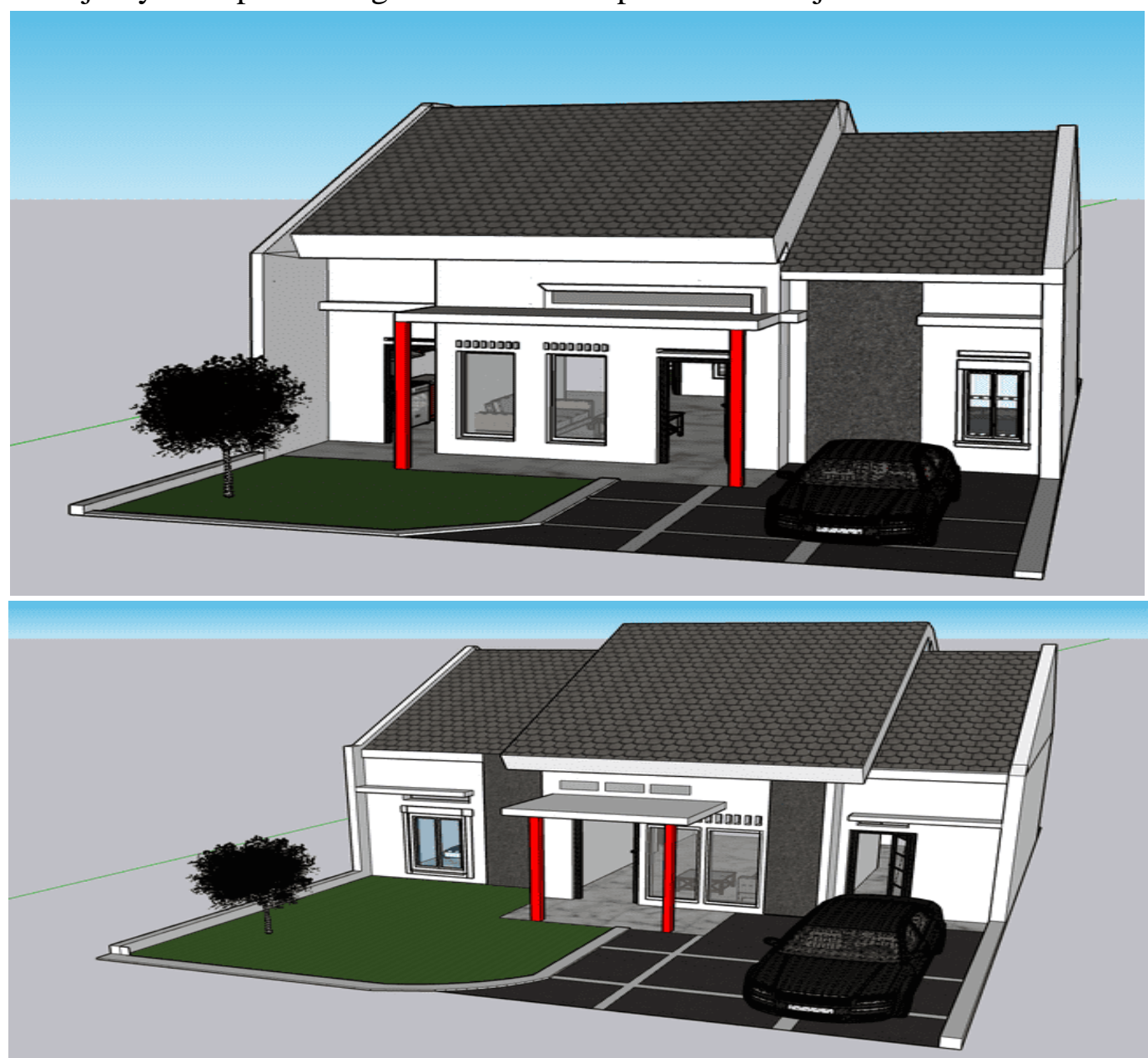

Gambar 4. Rumah type 45 dan 54

Pada gambar 4 dan 5 setelah melakukan modelling dan texturing sebelum ke tahap penganimasian. Proses pada gambar 6 yaitu merender menggunakan plugins v-ray pada sketchup 2020. 


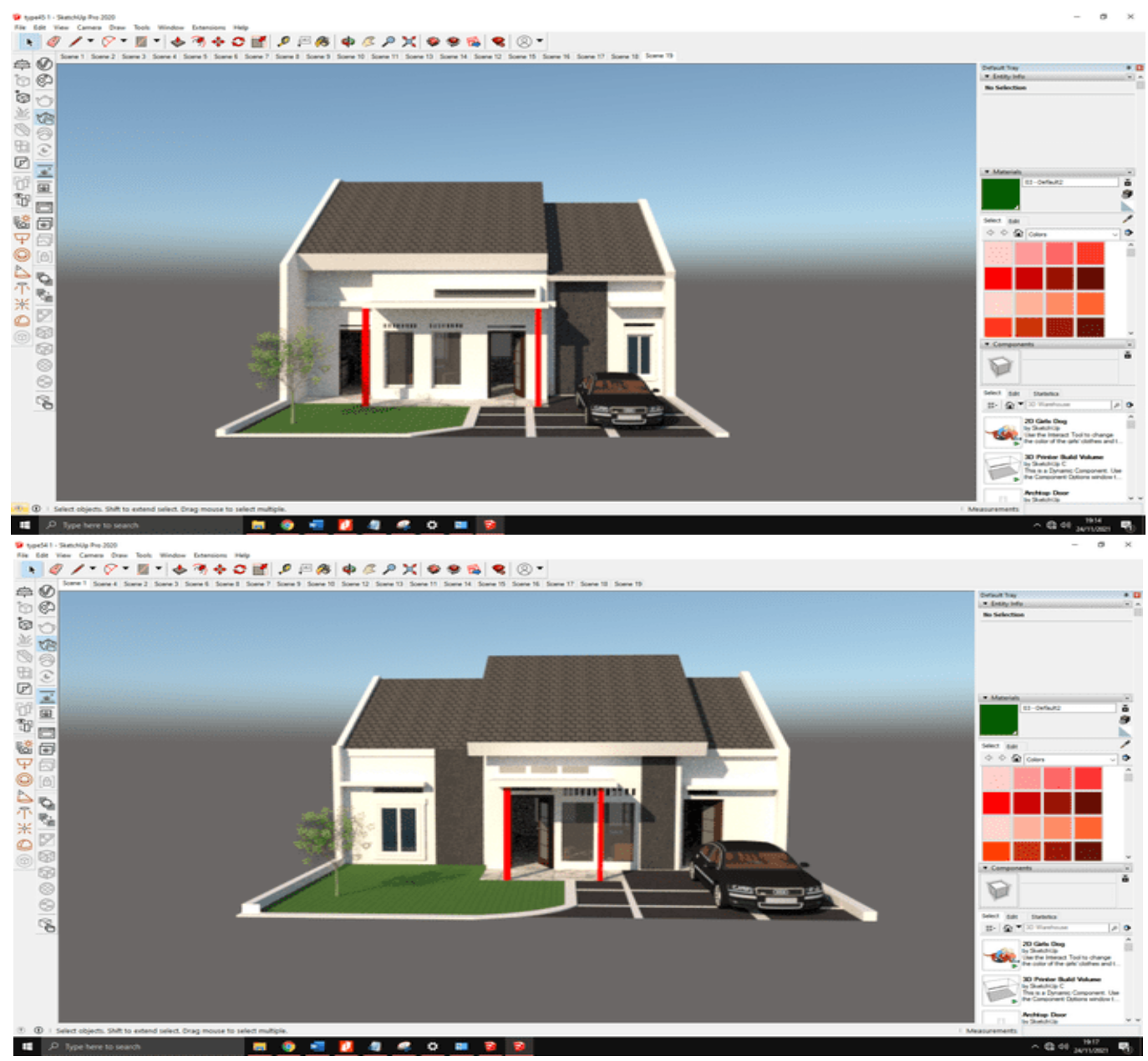

Gambar 5. Proses rendering

Pada gambar 6 proses rendering menggunakan plugins v-ray rumah type 45 dan 54 supaya terlihat lebih baik dalam segi kecerahan dan penampilan. Selanjutnya proses penganimasian kamera yang disesuaikan dengan storyboard menggunakan aplikasi sketchup.

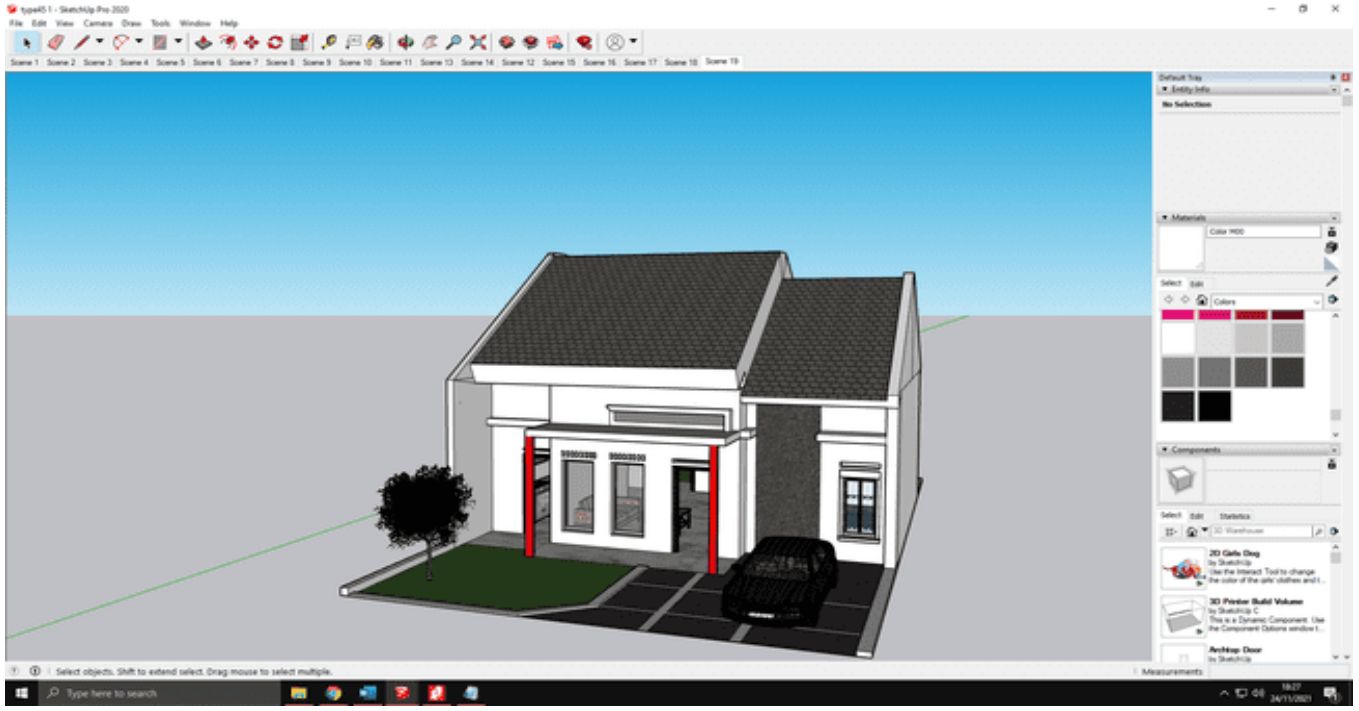




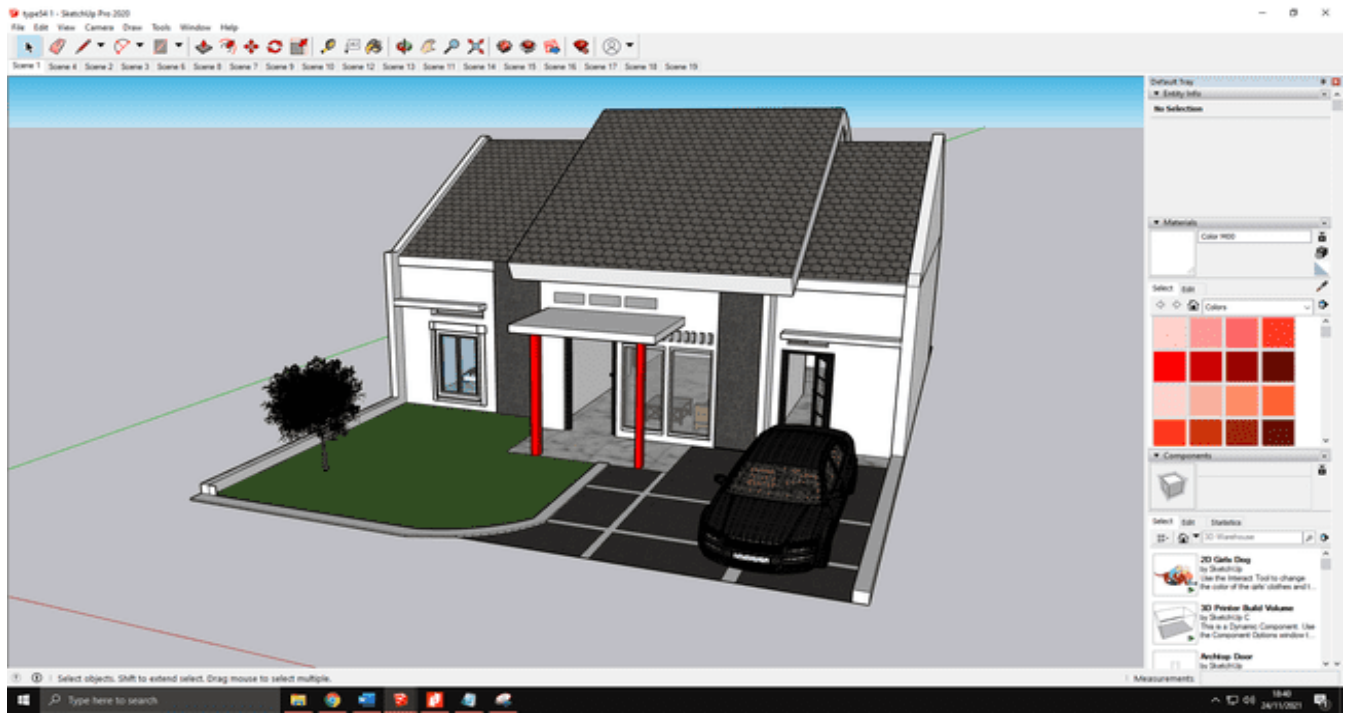

Gambar 6. Proses animasi menggunakan sketchup.

Pada Gambar 7 proses menganimasikan gambar yang sebelumnya hanya diam menggunakan sebuah kamera.

5. Testing

Tahap testing dilakukan dengan menjalankan video dan dicek ada atau tidaknya kesalahan dalam video animasi tersebut. Apabila masih kurang sesuai akan diperbaiki dan apabila berjalan baik akan dilanjutkan ke tahap berikutnya.

a. Alfa Test

Proses pencocokan rancangan animasi dengan hasil animasi yang telah dibuat sudah sesuai dengan kebutuhan storyboard dan kebutuhan konsep cerita.

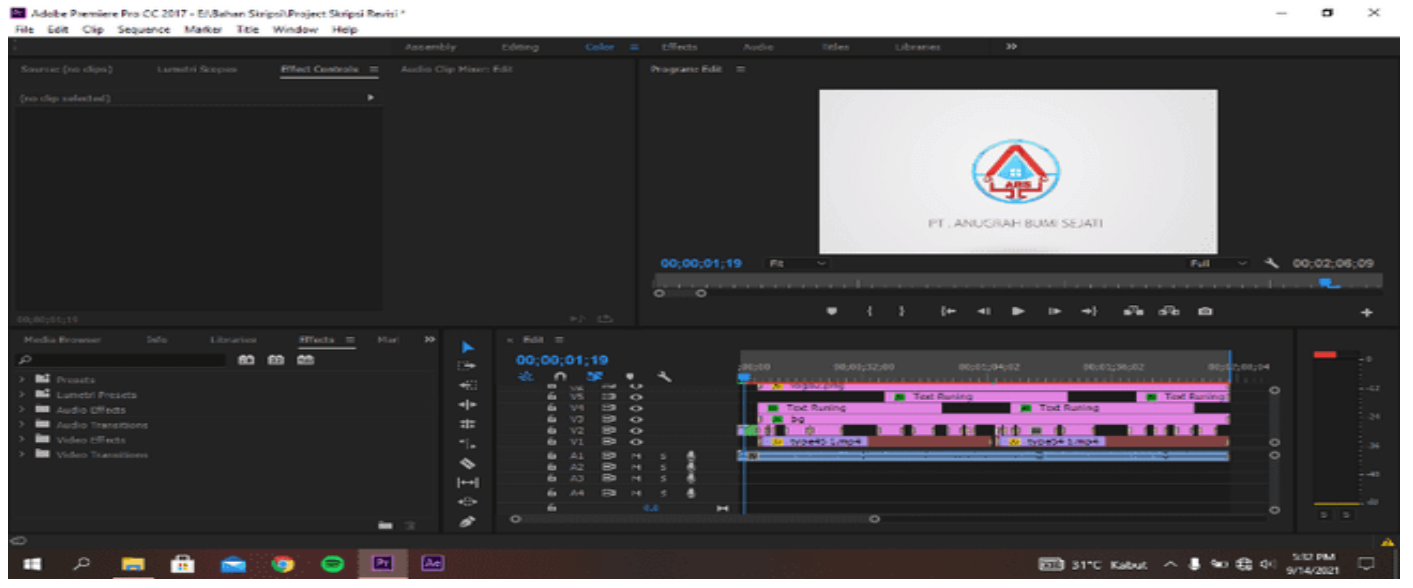

Gambar 7. Alfa test pada adobe premier cc

Berdasarkan Gambar 8 mengedit untuk menambahkan logo opening dengan logo perusahaan pada awal video animasi untuk mengenalkan perusahaan tersebut yang menangani perumahan bhumi nirwana dan backsound untuk membahkan kesan menarik. Untuk pergerakan kamera dilakukan pada aplikasi sketchup 2020 sehingga bisa langsung menjadi sebuah video dan di edit kembali menggunakan adobe premier.

\section{b. Beta Test}

Selanjutnya pengujian ini dilakukan untuk mengetahui respon audience. Tahap ini 
dilakukan dengan menyebarkan kuesioner untuk memperoleh informasi dari responden. Pengujian ini dilakukan untuk mengetahui apakah animasi sudah sesuai dengan kebutuhan PT. Anugrah Bumi Sejati sebagai salah satu sarana untuk media promosi perumahan yang dimiliki PT. Anugrah Bumi Sejati:

Tabel 2. Hasil beta test

\begin{tabular}{|c|c|c|c|c|c|}
\hline \multirow[t]{2}{*}{ No. } & \multirow[t]{2}{*}{ Aspek - Aspek } & \multicolumn{4}{|c|}{ Penilaian } \\
\hline & & $\mathrm{K}$ & $\mathrm{C}$ & B & SB \\
\hline 1 & $\begin{array}{l}\text { Penggunaan logo pada Awal Video Menggunakan } \\
\text { Teknik Low Poly Membantu Memperjelas Siapa } \\
\text { Yang menangani Perumahan tersebut }\end{array}$ & 0 & 5 & 8 & 17 \\
\hline 2 & $\begin{array}{l}\text { Backsound yang digunakan pada Video Promosi } \\
\text { Dengan Teknik Low Poly Membantu Memperjelas } \\
\text { Suasana Pada Setiap Adegan Pada Animasi Tersebut }\end{array}$ & 0 & 5 & 13 & 12 \\
\hline 3 & $\begin{array}{l}\text { Penggunakan Teknik Low Poly Sudah Sesuai } \\
\text { dengan Type Rumah yang ingin di Promosikan yaitu } \\
\text { Rumah Type } 45 \text { dan } 54\end{array}$ & 1 & 6 & 12 & 11 \\
\hline 4 & $\begin{array}{l}\text { Keluwesan gerakan Kamera Pada Video Promosi } \\
\text { Perumahan Dengan Teknik Low Poly Tidak Kaku }\end{array}$ & 1 & 4 & 12 & 13 \\
\hline 5 & $\begin{array}{l}\text { Video Animasi Perumahan Menggunakan 3D } \\
\text { Dengan Teknik Low Poly Sesuai dengan Kebutuhan } \\
\text { Promosi }\end{array}$ & 0 & 4 & 11 & 15 \\
\hline & Total & 2 & 24 & 44 & 68 \\
\hline
\end{tabular}

Keterangan Penilaian : $\quad$ K : Kurang $\quad$ : Cukup

$$
\text { B : Baik SB : Sangat Baik }
$$

Dari tabel 2 memberikan kuisioner ke 30 orang random dan pihak PT. Anugrah Bumi Sejati yang akan menggunakan video promosi tersebut responden dari rentan usia 19-30 tahun dengan jumlah pertanyaan pada responden sebanyak 5 pertanyaan maka total skor 138 , Dari hasil kuisioner didapat pernyataan sangat baik 68 dan pernyataan baik 44 , cukup 24 dan kurang 2 penyataan.

\section{Aspek Pertanyaan 1-5}

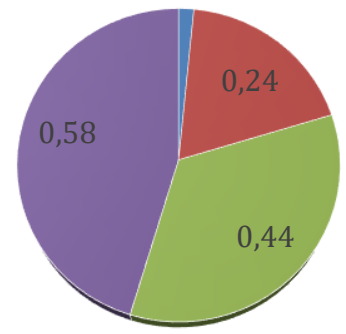

- Kurang - Cukup " Baik - Sangat Baik

Gambar 8. Grafik persentase penilaian 
K : Kurang 2/100x 100\%=0,02\% C : Cukup 24/100x 100\%=0,24\%

B : Baik 44/100x 100\%=0,44\% SB : Sangat Baik 68/100x 100\%=0,68\%

Dari gambar 9 aspek-aspek pertanyaan nomor 1 sampai 5 yang menyatakan sangat baik $0,68 \%$, kemudian cukup $0,24 \%$, sedangkan presentase yang menyatakan baik $0,44 \%$, dan kurang $0,02 \%$.

\section{Distribution}

Tahap ini video animasi akan disimpan dalam suatu media penyimpanan, tahap ini juga bisa digunakan sebagai evaluasi untuk pengembangan produk yang telah jadi agar menjadi lebih baik. Output video animasi yang sudah dibuat akan dipublikasi melalui karyawan PT. Anugrah Bumi Sejati. link video https://youtu.be/5jqitraTliU.

\section{KESIMPULAN}

Berdasarkan hasil pengujian dan analisa pada pembuatan media promosi tiga dimensi modelling bangunan pada perumahan Bhumi Nirwana diambil kesimpulan sebagai berikut animasi tiga dimensi modelling bangunan Pada perumahan sebagai media promosi berbasis multimedia telah berhasil di bangun dengan menggunakan teknik low poly. Animasi ini dapat mendeskripsikan mengenai keadaan bangunan yang ada diperumahan bhumi nirwana karanggintung untuk mempromosikan perumahan milik PT. Anugrah Bumi Sejati kepada calon pembeli yang ingin melihat dengan detail gambaran rumah yang di pasarkan oleh PT. Anugrah Bumi sejati.

\section{SARAN}

Penggunakan Teknik Low Poly pada animasi 3D memiliki masih kekurangan yaitu objek masih memperlihatkan lekuk kasar dan kurang realistis. Garis untuk membuatnya juga hanya sedikit dibandingkan dengan high poly salah satu cara supaya terlihat realistis dengan menggunakan vray.

\section{DAFTAR PUSTAKA}

[1] L. Sunarya, P. O. A. Sunarya, A. A. Fajar, and M. F. Abdillah, "Media Video Sebagai Penunjang Promosi Pada Days Hotel \& Suites Tangerang," Technomedia Journal, vol. 6, no. 1, pp. 66-81, 2021.

[2] J. J. Bintarto and I. S. I. Lestari, "Pemanfaatan Video Animasi 3D sebagai Media Promosi Wisata Kota Medan (Studi Kasus: Kawasan Medan Heritage)," Visualita Jurnal Online Desain Komunikasi Visual, vol. 9, no. 1, pp. 123-142, 2020, doi: 10.34010/visualita.v9i1.3733.

[3] M. Azmi, "PENGARUH IKLAN, PROMOSI PENJUALAN, DAN BRAND IMAGE TERHADAP MINAT BELI ULANG (Studi Pada Pengguna Shopee)." Universitas Bakrie, 2020.

[4] N. Mulyani, "Perancangan Proses Pra Produksi Film Animasi 3D Legenda Putri Merak Jingga," JURTEKSI (Jurnal Teknologi dan Sistem Informasi), vol. V, no. 2, 2019.

[5] U. Rahardja, N. J. Tejosuwito, and F. S. Armansyah, "Perancangan Aplikasi Pen+ Berbasis Mobile untuk Memudahkan Kinerja Dosen pada Perguruan Tinggi," Technomedia Journal, vol. 1, no. 2, pp. 50-60, 2017.

[6] A. Salsabila, R. Yunita, and C. Rozikin, "Identifikasi Citra Jenis Bunga menggunakan 
Algoritma KNN dengan Ekstrasi Warna HSV dan Tekstur GLCM," Technomedia Journal, vol. 6, no. 1, pp. 124-137, 2021.

[7] P. Nuning Indah, "Penggunaan Media Video Call Dalam Teknologi Komunikasi," Jurnal Ilmiah Dinamika Sosial, vol. 1, pp. 202-224, 2017.

[8] I. Binanto, Multimedia Digital - Dasar Teori Dan Pengembangannya, Nikodemus. Yogyakarta: Andi Offset, 2019.

[9] J. J. Bintarto and I. S. I. Lestari, "Pemanfaatan Video Animasi 3D sebagai Media Promosi Wisata Kota Medan (Studi Kasus: Kawasan Medan Heritage)," Visualita Jurnal Online Desain Komunikasi Visual, vol. 9, no. 1, pp. 123-142, 2020, doi: 10.34010/visualita.v9i1.3733.

[10] R. Fauzyah and E. Franzia, "Motion Graphic Promosi Pasar Papringan Di Temanggung, Jawa Tengah," Jurnal Dimensi DKV Seni Rupa dan Desain, vol. 3, no. 2, p. 159, 2018, doi: 10.25105/jdd.v3i2.3602.

[11] N. Mulyani, "Perancangan Proses Pra Produksi Film Animasi 3D Legenda Putri Merak Jingga,” JURTEKSI (Jurnal Teknologi dan Sistem Informasi), vol. V, no. 2, 2019. 